\title{
Highly ordered anodic porous alumina membrane and its surface modification approaches for biomedical application
}

\author{
${ }^{\mathrm{a}}$ Manju Singh, ${ }^{\mathrm{b}}$ Gobind Das \\ ${ }^{a}$ University of Genova, Genova 16132, Italy \\ ${ }^{b}$ Italian Insititue of Technology, via Morego, 30, 16163 Genova, Italy
}

\begin{abstract}
During recent years, the anodization of aluminum, due to its great commercial significance, represents one of the most important and widespread method used for the synthesis of ordered nanostructures. Whose geometry is controlled by diverse synthesis factors which include the voltage applied, the temperature of the electrochemical environment in which the synthesis is carried out, the reagent used to etch the aluminum metal and the time period of anodization. As anodic porous alumina (APA) has high porosity, pores with high aspect ratio with highly ordered pores. The matrix is well-suited for biomedical applications such as protein separation, purification, biomolecule detection, drug delivery protein crystallography and cell cultures because the biological macromolecules can easily fit into the pores of the matrix without the loss of primary biological action. In combination with surface engineering and nanobiotechnology diverse surface modifications are now being realized with nanoscale pore structures of APA that can provide high selectivity to archive a variety of applications based on specific molecular characteristics. This review observes how the structure and properties of APA related to their present and prospective uses for research in biotechnology. In addition, the role of APA are also covered in areas including, sensitive detection methods, microarrays and other molecular assays, and in creating new nanostructures for further uses within biology.
\end{abstract}

Keywords: Anodic porous alumina (APA, Biomedical applications, highly ordered, Pores, Protein separation.

\section{INTRODUCTION}

The biomaterials community has excelled in creating materials that are either completely inert (e.g., hip prosthesis) or completely biodegradable (e.g., absorbable structures) by minimizing cell adhesion, protein deposits and encapsulation. This is essential because biological reactions reduce the ability of active medical devices to interact with the biological environment. Biosensors and drug delivery implants are active medical devices that must be capable of functioning over months, years, and possibly decades. These devices must also show functional stability under an extensive range of biological conditions. The functional lifetime of an active medical device will be dramatically increased if biofouling (especially protein absorption) and inflammation are minimized.

Nanoporous membranes have rare or exciting properties, which have fascinated deep attention from nanotechnologists, material and medical scientists. Membranes with nanometer-scale features have many applications, such as in optics [1], electronics [2], catalysis [3], selective molecule separation [4-6], filtration and purification [7], biosensing as DNA-microarray or protein-chip application [8-10], and single-molecule detection [11-13]. These materials have usually a specific surface area. The functioning of biosensors is enhanced when nanoporous materials are used because of their large surface area and also due to their ability in size-selective infiltration. Nanopores procedure is challenging as it not easy to have an effective infiltration of molecules whose size is of the matching order of the pore radius. There is a relation between ease of infiltration and level of sensor response for the detection of biomolecules in nanopores. One of the interesting features of nanopores is high aspect ratios (pore diameter vs pore length) [15] which serve as selective portals in a way that resembles the way pores in living cells sense or acquire precise compounds and can serve as an operational support for chemical purifications and separations. Other attractive types include nanoporous materials of silica/glass and a range of metal foams and metal oxides. The latter group includes oxides capable of selfassembling into nanoporous structures under anodizing conditions and can be formed from metals such as tin, titanium and aluminum. The nanoporous forms of aluminum oxide have attracted the attention of materials scientists and electrochemists for a long time because the modifiable and ordered nanochannel array material provide facility for significant applications [22-24]. In the last 35 years or so, nanoporous membranes with a reasonably uniform pore-size distribution have become commercially available. Indeed, nanopore-molecule interactions were described by experiments and theory following the development of track etched membranes in the 1970s [16]. Highly ordered nanoscale surfaces can greatly enhance some optical and physical detection methods such as surfaced enhanced Raman spectroscopy (SERS). A typical anodic porous alumina (APA) has columnar hexagonal cells with central, cylindrical uniformly sized holes ranging from 10 to $200 \mathrm{~nm}$ in diameter, pore density as high as $10^{-8}-10^{-11}$ pores $/ \mathrm{cm}^{2}$ and the film thickness varying from 0.1 to $300 \mathrm{~nm}$, pore length 
about $60 \mu \mathrm{m}$ (see table 1 and figure 1) [17-19]. Additionally, these dimensions are modifiable. It has been reported that the pore density and pore size of the APA can be controlled by the anodizing voltage and the solution composition, whereas the membrane thickness can be adjusted by the charge passed during the anodic electrolysis [21]. Aluminum is one of the lowest valency metals not commonly found in nature, the oxide is highly insoluble and unlike many other aluminum salts, non-toxic which results in excellent biocompatibility. APA has a low background with respect to many detection techniques, including fluorescence microscopy. Additionally, aluminum oxide does not change volume greatly with temperature changes or on wetting, it is compatible with a wide range of solvents and is exceptionally thermostable (some forms withstand temperatures in excess of $1000{ }^{\circ} \mathrm{C}$ ). The manufacture of nanoporous oxides is not recent, and the availability of commercial forms over the last few decades may have contributed to the wide range of ingenious applications. To date over 500 patents have been filed on the manufacture or use of anodic alumina. Lastly, those nanoporous alumina membrane materials that do exist can be used as templates to produce other nanoscale materials with added suitable properties. In the subsequent section surface modifications to improve membrane properties for biocompatibility and fouling resistance will be highlighted. Further, biomedical applications of anodic nanoporous alumina materials will be reviewed. Further, key scientific challenges and future directions will be discussed in the concluding remarks. Moreover, this review will also examine how the structure and properties of APA connect with its present and potential uses within research and biotechnology areas including microbiology, mammalian cell culture, sensitive detection methods, microarrays and other molecular assays, and in creating new nanostructures with further uses within biology

\section{Preparation Of Anodic Porous Alumina (Apa) Membrane For Electrochemical Method}

Preparation on two step anodization for ordered arrays with straight holes in naturally ordering processes and degree of the ordering of the hole configuration at the surface of the anodic porous alumina is low because the holes develop randomly at the initial stage of the anodization [43]. To improve the ordering of the surface side of the anodic porous alumina, two-step anodization has been effectively adopted [44]. The first anodization process consists of a long-period anodization to form the highly ordered hole configuration at the oxide/Al interface and the second anodization is performed after the removal of the oxide formed in the first anodization step. After the removal of the oxide, an array of highly ordered dimples was formed on the Al, and these dimples can act as initiation sites for the hole development in the second anodization. This process generates an ordered hole array throughout the entire oxide layer. In figure 2 shows the schematic diagram of fabrication of ideally ordered porous alumina using an imprint stamp. More, APA template with different pore size and wall thickness were produced using different electrolyte solution (acid), the voltage applied, the temperature of the electrochemical environment in which the synthesis is carried out, the reagent used to etch the aluminum metal and the time period of anodization. Additionally, the preparation of a porous alumina mask can be used several types of fabrication method given in table 2 .

\section{CHEMICAL REACTION} be written as:

The Chemical reaction of anodization of aluminum appears simple. For example, the main reaction can

$2 \mathrm{Al}+3 \mathrm{H}_{2} \mathrm{O} \rightarrow \mathrm{Al}_{2} \mathrm{O}_{3}+3 \mathrm{H}_{2}$

This reaction is right, however does not represent the specifics of the entire electrochemical process. It is crucial to know the chemical reactions at electrolyte/oxide and oxide/metal limits independently. It is definite that, when electric field is applied, aluminum at the oxide/metal mechanism will be oxidized into $\mathrm{Al}^{3+}$ cations: $\mathrm{Al} \rightarrow \mathrm{Al}^{3+}+3 \mathrm{e}$. Several of these cations transfer through the oxide layer and are liquefied into the electrolyte (in a case of porous APA) or form oxide at the electrolyte/oxide interface (in a case of nonporous APA). The hydroxide will finally decompose to form oxide. In the case of APA, even hydroxide of aluminum forms as an intermediate phase, it will decay very quickly and no measurable hydroxide layer appears. At the electrolyte/oxide interface, $\mathrm{Al}_{2} \mathrm{O}_{3}$ is liquefied in electrolyte. The oxide anions are directed by the electric field to the oxide layer, leading to the formation of $\mathrm{Al}_{2} \mathrm{O}_{3}$ at the oxide/metal interface. However, these oxide anions are not sufficient for the newly made oxide layer. A high quantity of anions must be provided from dissociation of water at the electrolyte/oxide interface. A water-splitting reaction: $\mathrm{H}_{2} \mathrm{O} \rightarrow 2 \mathrm{H}_{+}+\mathrm{O}^{2-}$ or $\mathrm{H}_{2} \mathrm{O} \rightarrow \mathrm{H}^{+}+\mathrm{OH}^{-}$was thus projected [47, 48]. It was stated that dissociation of water not only supplies anions to the oxide layer, but also shows a key role in leading the porosity of the porous APA films and the overall reaction at the electrolyte/oxide interface can be written as:

$$
\mathrm{Al}_{2} \mathrm{O}_{3}+n \mathrm{H}_{2} \mathrm{O} \rightarrow 2 \mathrm{Al}^{3+}+(3+n-x) \mathrm{O}^{2-}+x \mathrm{OH}^{-}+(2 n-x) \mathrm{H}^{+}
$$


where $n$ is the ratio of the dissociation proportion $\mathrm{n}$ of water to the dissolution rate of $\mathrm{Al}_{2} \mathrm{O}_{3}$ and $x$ is the ratio of $\mathrm{O}^{2-}$ and $\mathrm{OH}^{-}$, which has not yet been determined [49]. In addition to the main reactions above, some anions in electrolyte may also be incorporated in the aluminium oxide layer. For example, an oxide film grown in phosphoric acid electrolyte may contain phosphorus species, probably as $\mathrm{PO}_{4}{ }^{3-}$ anions [50, 51]. These big anions transfer far slower than $\mathrm{O}^{2-} / \mathrm{OH}^{-}$anions and are incapable to move to the oxide/metal interface [52]. Therefore, water in electrolyte is still the key source of oxygen for the formation of the oxide films [53].

\section{General Structure Of Anodic Porous Alumina}

The geometrical structure of anodic porous alumina is schematically represented as a honeycomb structure containing of a close-packed array of columnar alumina units called cells, each having a central straight hole see figure 3, which are often categorized by given parameters such as a pore diameter, wall thickness, barrier layer thickness and interpore distance (cell diameter). The uniform pore diameter, which is easily controllably by altering the anodizing conditions shown figure 4, can range from a few nanometers to hundreds of nanometers. The depth of fine parallel channels can even exceed $100 \mathrm{~mm}$, a characteristic which makes anodic porous alumina one of the best chosen nanostructures with a high aspect ratio and high pore density, the dependence of the depth of the ordered holes on the applied voltage for the anodization in oxalic acid solution has studied in [54]. The most appropriate voltage for maintaining the ideal ordering of pores is 40 $\mathrm{V}$, and the ideal pore configuration with high aspect ratio cannot be maintained under other applied voltages. The major anodic film factors are directly dependent on the applied voltage. The cell size, corresponding to the hole interval, is determined by the applied voltage used for the anodization; the cell size determines he applied voltage with the applied voltage. The value of the constant of the cell size combined by the applied voltage is approximately $2.5 \mathrm{~nm} \mathrm{[31]} \mathrm{and} \mathrm{it} \mathrm{is} \mathrm{given} \mathrm{by} \mathrm{the} \mathrm{equation}\left(D_{\text {int }}=k U\right)$ where $D_{\text {int }}$ is interpore distance of cell, $U$ $i$ the applied cell potential and $k$ is a proportionality constant.

Generally, with increasing anodizing potential is seen to increase the interpore distance. Additionally, the hole size is dependent on the electrolyte configuration, temperature, period of anodization as well as applied voltage. The hole size is also controlled by the pore spreading treatment by dipping the porous alumina in an appropriate acid solution after the anodization. The cell size usually ranges from 10 to $500 \mathrm{~nm}$ and the holes size from 5 to $400 \mathrm{~nm}$ [55] depending on the anodizing and post-anodizing conditions. The depth of the holes (thickness of the oxide films) has a linear relationship with the period of the anodization. A side effect of APA manufacture, occasionally seen on commercial APA, is a phenomenon called "hot spots" which are strong points of fluorescence on a low background material. In other situations, such as gold or silver coated APA, hot spots formed purposely may be a suitable image development practice [56]. For example, in a paper [57] where APA substrate with hexagonal periodicity [15] was prepared at $+7^{\circ} \mathrm{C}$ external bath temperature with electrolyte stirring, by controlled modification of a $250 \mathrm{~nm}$ thick foil of ultrapure (99.999\%) aluminum as anode, in the same open electrochemical cell configuration. The anodization was carried out in the aqueous solution of oxalic acid to obtain the desired pore size and cell thickness. The estimated design of the nanostructured APA template is shown in Figure 5 (a). Further, Gold was thermally evaporated onto the APA substrates (APA) with deposition rate of $0.5 \AA / s$ until a final total thickness of $25 \mathrm{~nm}$ was reached. The sample holder was always rotated at 1 RPM in order to improve the homogeneity and the morphological excellence of the gold layer. The substance of interest was deposited over subsequent gold-coated APA substrate termed as 'AuAPA' using chemisorption technique. In this method, the substrate was dipped in a solution containing the molecule of interest. The substrate was removed after $20 \mathrm{~min}$ from the solution and then, gently, rinsed to remove excess molecules those are not attached directly to the metal surface. Then, the samples were dried in $\mathrm{N}_{2}$ flow, and lastly stored in a desiccator before SERS measurements. Cresyl violet (CV) dyes and glycine amino acid were tested for SERS probes with the concentration about $10^{-6} \mathrm{M}$ [58]. SEM images of APA substrate before and after gold-coating of $25 \mathrm{~nm}$ are shown in figures 5 (b and c).

\section{Highly Ordered Anodic Porous Alumina Membrane}

Under certain anodization conditions, continuous oxidation results in self-organization of the pores which consequently create a very well-organized structure [59]. This has focused to the development of a twostep oxidation method, where a sacrificial oxidation layer is formed till the oxidation reaches a fixed state. Subsequently a well-organized porous structure is straight designed during the following oxidation step [43]. By elimination of the oxide layer left the core aluminum imprinted with the periodic structure. APA made under these self-organization settings has a porosity of about $10 \%$ [31] and has defect-free places up to few microns in size. The porosity of a hexagonal structure is given by the equation 3, where the radius of the pore is $r$ and the interpore spacing $D_{\text {int }} r / D_{\text {int }}$ is constant for self-ordered porous alumina, the optimum porosity is around $10 \%$. Some of the parameters in which the optimum porosity is around $10 \%$ have given in table 3 . Note that the slightly larger pore diameter of the $\mathrm{H}_{2} \mathrm{SO}_{4}$ sample is due to chemical attack of the pore walls. Note that in the disordered growth regime, the porosity can be significantly larger or even smaller than $10 \%$ [58]. 


$$
\boldsymbol{P}=\frac{2 \pi}{\sqrt{3}}\left(\frac{r}{D_{\text {int }}}\right)^{2}
$$

The necessity for a constant voltage does not permit lift-off by a progressive voltage reduction. Thus, well ordered APA is generally synthesised from thin aluminum films. After anodization, the substrate is etched, e.g. with an aqueous $\mathrm{CuCl}_{2}$ solution. Instead, etching can be achieved with saturated $\mathrm{HgCl}_{2}$ followed by $5 \%$ phosphoric acid. These methods remove the remainder of the aluminum and open the pores to create a symmetrical membrane. The limited number of known self-ordering conditions puts restrictions on the availablemembrane formats. More flexibility is introduced by premolding the aluminum film with an imprint stamp [44].

Throughout following anodization, the imprinted design is reproduced in the oxide, resulting in extraordinarily ordered arrays. Nanopores have other attractive properties: narrow pores with high aspect ratios (pore diameter vs pore length) [60] can act as selective portals in a way that mimics the way pores in cells sense or take up specific compounds and can be effective supports for chemical purifications and separations. An oxide layer of $>400 \mathrm{~nm}$ was formed; anodization at higher voltages proved to be stable but when Anodization outside the setup window of small anodization can effect in breakdown of the oxide film [61]. Alternatively, the maximum aspect ratio of well-ordered pores that can be attained throughout the imprinting of contradictory arrangements stay limited [62]. Self-ordering systems can also be formed at high anodization voltages which have been shown recent years, [63]. This hard anodization method formed shaped and a well-ordered structure in a rationally wide operation system. An increased anodization rate is also due to higher voltage $(>50 \mu \mathrm{m} / \mathrm{h}$ compared to $2-6 \mu \mathrm{m} / \mathrm{h}$ for mild anodization). Instead, the porosity attained was reduced to only $3.3 \%$. The availability of altered anodization schemes has led to the fabrication of extra advanced structures. An oxide with an interchanging pore diameter could be obtained by switching mild and hard anodization, [64]. The creation of ragged pores was also established by an additional innovative fabrication method [65]. By distorted voltages, Slopes of different diameter nanopores over spaces up to a centimetre were attained [66]. Concluded inclusion anodic oxidation with selective aluminium etching, very thin APA membranes that were maintained by unetched aluminum were attained; these membranes showed better flow rates during filtration [67].

\section{Surface Modification And Functionalization To Improve Apa Membrane Properties}

Advances in protein screening, organic and inorganic molecular development, and sensing of toxins/viruses have enhanced the requirement for membranes with uniform pore size and a large dynamic range of biomolecule size selection $(\sim 1 \mathrm{~nm}$ to $1 \mu \mathrm{m})$. Surface modification permits adjustment of the simple quality of alumina, e.g. not only the reflectivity, hydrophobicity and surface charge, but also membrane selectivity, antifouling resistance and the recruitment of biomolecules in specific and potentially high-throughput assays. Added extra molecules bound to an inert aluminum oxide surface may look like an unrealistic objective; but they add capabilities to the high surface area [68-75]. Aluminum oxide surfaces can be modified in several ways see table 4, for example the adsorption of poly-L-lysine to APA results in positively charged surfaces that can bind DNA fragments by electrostatic interactions. This has been exploited for the fabrication of a fluorescence resonance energy transfer (FRET) based sensor with single pore resolution [76] and cholesterol sensor [77] similarly, the adsorption of poly (diallyldimethylammonium chloride) can facilitate gold nanoparticle binding [78]. In situ polymer formation on APA has been proved by plasma polymerization [79]. This produces an amine-terminated surface, but also lessens the actual pore diameter. A more efficient method to modify nanoporous membranes is by atomic layer deposition (ALD). ALD is a film growth technique that utilizes alternating, self-limiting chemical reactions between gaseous precursor molecules and a surface to deposit material in an atomic layer-by-layer fashion [80] resulting in an integrated architecture having narrow pore size distribution. Layer by layer assembly or self-assembled monolayers (SAMs) resulting in packed and unbroken surface coverage, and that it does not markedly variation the structural properties of the substrate. The adsorption of alkanethiols offer a suitable method to assign functional groups to metal substrates such as gold, silver and copper that can be used in membrane technology, especially in nanofiltration [81] and then used to prepare ion selective membranes with controllable $\mathrm{pH}$-dependent permselectivity [82]. Freshly, much success has been obtained by functionalizing implant surfaces with polyethylene glycol (PEG) [83]. The benefits of monolayer development are that it is typically based on self-assembly, of n-alkanoic acids on APA is possible, but as this adsorption were is reversible, the subsequent monolayers were under aqueous environments [84]. Most reports, still, deal with organosilanes. This is important, as the packing density and stability of organosilane monolayers is known to be controlled on alumina in contrast to other substrates [85]. The deposition of silica former to monolayer formation is suggested to increase monolayer stability, however complicates the modification method [72]. Stable monolayers on alumina also form by phosphoric acids [85, 87], however there is only one example of the adsorption of these compounds onto APA [88], may be because of the limited marketable availability of functional phosphonic acids. Finally, chemisorption of terminal alkynes onto APA also results in the creation of stable monolayers which was newly exposed [89]. To change the 
surface charge of APA has been modified by applying organosilanes [70], and to produce a superhydrophobic material by hexamethlydisilane (HMDS) [90,91] and to lessen membrane fouling [92, 93]. See the mostly used classes of compounds are to form monolayers on anodic aluminum oxide as including organosilanes, carboxylic acids, and phosphonic acids for some surface modification of anodic aluminum oxide (APA) membranes in figure 6 .

When biomedical implants come in connection with physiological surroundings, primarily three types of reactions happened to bound the long-term usage. These are (1) biofouling, (2) immune reaction as determined by biocompatibility, and (3) degradation and loss of implant material due to corrosion, dissolution, or leaching. Numerous approaches are being discovered to report these concerns such that the future medical implants interact with the host in a controlled and a predictable manner. Diamond-like carbon (DLC) thin films are another suitable material for implantable biosensors. The term diamond-like carbon is used to describe amorphous carbon that contains $\mathrm{sp}^{3}$ hybridized carbon atoms. In a recent study, [94] demonstrated that DLCcoated nanoporous alumina membranes remained free from fibrin or platelet aggregation after exposure to human platelet rich plasma. In that paper shows that no fibrin networks or platelet aggregation were observed on the surface of the DLC-coated nanoporous membrane (100 nm pore size) after exposure to human platelet rich plasma. Porous alumina is an alternative porous medium, which along with the major advantages of porous silicon offers high stability in aqueous environment at physiologically relevant $\mathrm{pH}$. For this reason porous alumina recently started to receive attention as a transducer matrix [95-97]. However, there has been only limited success in porous alumina transducers based on waveguide spectroscopy [96] and a prototype interferometric detection system that required a drying step and therefore, it could not be used for the design of real-time biosensor devices. Dronov reported an interferometric reflectance transducer based on nanoporous alumina films with a thin semi reflective metals coating [98]. In contrast to porous silicon, this material is highly stable in aqueous environment, does not require highly toxic and corrosive substances for its preparation and can be easily surface-modified using silane chemistry. He demonstrated that such a hybrid transducer can be successfully applied for the construction of optical immunoassays. This approach takes advantage of the low refractive index of porous alumina while providing sufficient reflectivity to generate a high fidelity interferometric reflectance spectrum in water. Also, he demonstrate that fine-tuning essential functional properties of the porous layer, its permeability and size restriction, can be accomplished by an additional chemical etching step following the anodization process. One can also envisage independent modification of the interior of the pores (e.g. with a receptor or antibody) and the semireflective metal layer (e.g. with an antifouling coating) in order to enhance the system's selectivity towards specific types of analytes. He expects composite porous alumina/metal-based interferometric transducers to find practical applications in biomedical diagnostics in the near future.

APA is highly well-suited substrate for surface enhanced Raman spectroscopy (SERS), which is an exceptionally sensitive, label-less and potentially real-time variant [99]. The surface enhancement effect is persuaded by strongly localized electromagnetic fields ('hot spots') that can be obtained by excitation of nanostructured metals. Hence, early studies used APA as a sacrificial template to form ordered metal nanostructures [100], Also, SERS-active substrates have been obtained by adsorption of silver and gold nanoparticles onto APA [101-104] These surfaces show increased sensitivity compared to planar surfaces not only because of the higher surface area, but also the optical waveguide effect. The latter was estimated to give rise to an additional enhancement of about three orders of magnitude [103] and corresponding substrates were used to detect concentrations of explosives to a sensitivity of one part in [103]. Moreover, APA was lined with a metal to obtain a surface with homogeneous SERS activity, which is hard to obtain by nanoparticle-based methods [105]. Gold deposition within the nanopores, combined with fine-tuning of the APA thickness, has been used to produce sensitive arrays [105]. Sputtering a well-ordered APA substrate with silver can result in the formation of hemispherical silver nanocaps on the outer surface. It was shown that the distance between the individual nanocaps is able to be fine-tuned, which makes these surfaces excellent SERS substrates [106]. In addition to homogeneous SERS activity, the advantages of these procedures are their easiness and scalability.

In the study [107] Cresyl Violet (CV) dye is extensively used in biology and medicine for histological stain see optical absorption spectrum and molecular structure in inset of figure 7a. The optical spectrum of CV shows the absorption peak at around $580 \mathrm{~nm}$. Though it is not fully in resonance with the excitation frequency for SERS measurement, minute resonance contribution can be expected because of the resonance frequency. SERS measurements were performed for CV dye, deposited on AuAPA SERS substrate, at different positions in the range of 300-1400 $\mathrm{cm}^{-1}$. Raman measurements were performed for CV on a flat non-patterned silicon wafer substrate and on flat gold surface as well, which can be considered as a positive control sample. The Raman spectrum of $\mathrm{CV}$ on $\mathrm{Si}$ surface, presented in figure 7(a), is relatively unremarkable, with an exponentially increasing fluorescence background and a single characteristic peak of $\mathrm{CV}$ at $591 \mathrm{~cm}^{-1}$ with low intensity, figure 7(b) SERS spectrum of CV is also illustrated, showing the CV spectrum due to an efficient fluorescence quenching by honey-comb structure. AuAPA SERS background spectrum and Raman spectrum of CV, 
deposited on flat Au surface, are shown in the inset of figure 7(c) SERS and Raman spectrum of glycin (an amino acid). A new possible way to produce large area SERS devices established by fabricated AuAPA substrates showing periodic hexagonal lattice $(100 \mathrm{~nm})$ with pore size of $60 \mathrm{~nm}$. This method permits the production of reproducible SERS substrates without involving cost effective lithographic techniques. Also, SERS analysis was performed for CV and glycine molecules, deposited by means of chemisorption techniques. The SERS enhancement factor ' $G$ ' was estimated to be around $10^{4}$ and $7 \times 10^{6}$ with respect to the flat gold surface and to the Si substrate, respectively. Numerical simulations of AuAPA device were performed showing a maximum value of electric fields in correspondence of the edges between gold and air-pores. Moreover, the electric field enhancement is supporting experimental findings. Organised study should be carried out by varying pore size and cell thickness. Thus, an optimization of ' $G$ ' could be achieved, opening a new route for the production of disposable SERS device.

\section{Application Of Anodic Porous Alumina Membrane For Biomedical Application}

Alumina membranes are a class of self-organized, highly ordered and biocompatible nanomaterials with regular pore size, uniform pore density and high porosity over a large scale, thus providing an increased surface area [1]. Over and above, nanoporous APA is optically transparent, electrically insulating, chemically stable, bio-inert and biocompatible [3]. These outstanding properties are beneficial for various applications figure 8 of APA membranes in biomedical ranging from biofiltration membranes [4-6], lipid bilayer support structures [7], biosensing devices [8-12] and implant coatings [13-16] to drug delivery systems with APA capsules [3,17-19] and scaffolds for tissue engineering [20-23]. In implantable drug delivery or immunoisolation devices, the membrane would function as a semipermeable compartment that holds the implant or drug while allowing passage of desired molecules in a controlled manner [108]. Nanoporous membranes are also the obvious choice for in-vitro analysis, including medical diagnosis, cell evaluation, and protein separation [109]. A key challenge has been to fabricate membranes with appropriate pore size, pore density, and pore size distribution properties, in order to maximize passage of analytes and minimize passage of fouling materials [108,110-111]. Furthermore, APA nanopores are not always used on their own. They also serve as widely used template for other biocompatible nanostructures such as gold and platinum nanopillars [24-26]. Moreover, the electrochemical production of biocompatible APA templates is often combined with pre-structuring approaches such as electron beam lithography to create localized nanostructures in the nanoporous templates [30-32]. The surface of APA nanopores can also be modified with versatile methods to tailor them for specific cell growth. Moreover, nanoporous APA membranes have a low background autofluorescence, which is advantageous for cell counting applications in particular [33]. Because of these outstanding biomaterial properties nanoporous APA membranes have gained increasing interest as cell-interface substrates for manifold cell types and biomedical applications. The pore diameter of nanoporous alumina membranes can also affect the behaviour of hepatic cells [112]. The material itself showed no cytotoxic effects and the cells adhered on the membranes even without any further surface modification. Recent progress in fabrication techniques has made it possible to make such ideal membranes in expensively. The major difficulty in creating closed-loop systems that function over long periods of time within the body is the poor in-vivo performance of implantable biosensors. Enormous research efforts in the past decade have been applied to automate biological analyses and to reduce sample consumption and cost. There has been a great push toward the micro total analysis system ( $\mu \mathrm{TAS})$ or lab-on-achip concept [113].

\subsection{SEPARATION AND SORTING BIOMOLECULES}

Separation and sorting is used for isolation and purification of molecules from various biological feed streams and is important in many fields including pharmaceutical industry, food industry and biotechnology. Many techniques, including size exclusion chromatography and gel electrophoresis of biopolymers, are currently used in separation science [113,114].

The basic principles that govern size-separation through nanoporous membranes remain the same; Biomolecule driven by electric potential. By summarizing the existing theory of solute transport through nanoporous membranes, it is evaluated in terms of hydraulic permeability $(\mathrm{L} p)$ and some sort of pore-size rating [115].The hydraulic permeability indicates the porosity of the membrane. It is defined as the solvent flux through unit area of the membrane under a unit pressure difference, and it is given by equation 4 , where $\mathrm{r} p$ is the pore radius, $\mathrm{y}$ is the solvent viscosity, and $(\mathrm{Ak} / \Delta x)$ is the ratio of surface porosity to the pore length. The pore size rating is usually expressed as molecular- weight cut off (MWCO). The MWCO is generally defined as the molecular weight for which $90 \%$ of the solute is rejected [116]. Rejection (R), which is related to ratio of the analyse concentration in the permeate $\left(C_{p}\right)$ and in the feed solution $\left(C_{\mathrm{f}}\right)$, is given by equation 5 .

$$
L_{\rho}=\left(\frac{r_{\rho}^{2}}{8 \eta}\right)\left(\frac{A_{k}}{\Delta x}\right)
$$




$$
R=1-\frac{c_{p}}{c_{f}}
$$

Although several membranes, such as those by Whatman are available for size-based filtration, these membranes do not have all the desired 'ideal' membrane properties to separate similar size biomolecules. See figure 9 about a plan comparison of charge-based separation via a Normal membrane and a thin alumina nanoporous membrane.

Further, the unmodified anodic aluminum oxide membranes without separate modification is used to studied the electrostatic sieving effect for separation of proteins with similar molecular weights, bovine serum albumin

(BSA) and bovine hemoglobin $(\mathrm{BHb})$ at $\mathrm{pH}=4.7$ (the isoelectric point of BSA) [117], Low ionic strengths exhibits large double layer thickness both on the surfaces of the protein as well the the charged surfaces of nanoporous membranes. The double layer thickness [118] is given by $\mathrm{L} d$ (equation 3 ).

$$
L_{d}=\left(\frac{s R T}{2 F^{2} q^{2} c}\right)^{1 / 2}
$$

Where $c$ is the concentration, $q$ is the charge number, $R$ is the gas constant, $T$ is the absolute temperature, and $F$ is the Faraday constant. The improved selectivity of the thin anodic alumina membrane results from the relatively large flux of the neutrally charged BSA and the low flux of the positively charged BHb when nanochannel diameters become close to protein size. This is ascribed to the strong electrostatic interaction and adsorption inside the charged pore of the membrane at low ionic strength. When the $\mathrm{pH}$ of a solution is equal to the $\mathrm{pI}$ (isoelectric point) of the protein it contains, the neutral molecules do not interact electrostatically with the surface of the membrane pores, which leads to a maximum flux across it. So protein can diffuse through the pore easily. At $\mathrm{pH}$ values above and below the $\mathrm{pI}$, charge interactions between the proteins, their counterions, and the pore surface lead to a decrease in trans membrane flux. Therefore, when pore size and protein size are close to each other, the transport of protein is highest at isoelectric point. Therefore, charge-based selection/separation is difficult to occur during a mixed protein transport experiment via the commercial alumina membrane even if one side of the membrane has similar pore size distribution as our thin anodic aluminia membrane. This shows the importance of pore size/geometry in order to make use of the electrostatic sieving effect for separation of proteins with similar molecular weights illustrates that the electrostatic interactions between proteins and pore walls are important factors in protein transport across porous membranes and that these interactions are complex. Previously, Gold nanotubule membranes have attracted attention because they can be used to control ion transport selectivity by external means, for example by changing the $\mathrm{pH}$ and ionic strength and applying electrical potentials [119-121].

In a more advanced study, an interesting development is the layered surface modification reported by [122-123], in which anodization and organosilane monolayer formation are repeated. This process allows one to further tune the transport properties of the membrane. By coupling (functionalized) inorganic nanoparticles to the APA surface, new properties may also be introduced to the substrate. This coupling can be enabled by modification of the APA with a polymer or organic monolayer [78], but can also be performed directly onto the APA. [67,124] Coupling of nanoparticles to the APA is often performed with the aim of Raman enhancement but also for the introduction of fluorogenic detection reagents. A modified APA membrane was created by covalently coupling fluorophore-loaded silica nanoparticles to the APA. As the fluorophore ( $\mathrm{pH}$ rodo, Invitrogen) displays $\mathrm{pH}$ dependent fluorescence, the resulting surfaces can be used for screening of strains of acid-producing bacteria. An exciting and commercially viable set of applications for functionalised surfaces is the recruitment of biomolecules for specific assays potentially massively parallel with a large number of binding sites (e.g. immobilized antibodies or oligonucleotides) for different targets [125]. An elegant example is the use of APA to create silica nanotubes that are able to display functional antibodies capable of distinguishing between drug enantiomers. Such a system can selectively bind one enantiomer. An extension of this idea was to reduce the affinity of the antibody, without eliminating selectivity, using DMSO as a co-solvent. This allows an APA surface to be used as a chromatography system efficiently billions of nano-chromatography columns in parallel, for the separation of high value biomolecules [74].

\subsection{BIOSENSOR}

Studies by Madaras \& Buck (1996) [126] others have indicated that biosensor membranes should exhibit low protein fouling, controlled porosity (e.g. minimal pore-to-pore variation) as well as low thickness values in order to enable the biosensor to rapidly respond to fluctuations in analyte concentrations. The enzyme glucose oxidase has also been encapsulated in APA membranes to develop electrochemical biosensors, which measure the enzyme activity [85]. Pore sizes in this study ranged from 30 to $80 \mathrm{~nm}$, and the outer surface of the biocapsule sensor was coated with the biopolymer chitosan to increase the enzyme stability within the capsule. 
When the pore diameter enhanced a larger amount of enzyme could be stored in the pores. For smaller diameters a slower response of the sensor was observed, which was slowest for a pore diameter of $40 \mathrm{~nm}$ in a $150 \mu \mathrm{m}$ thick pore. The large surface area of the nanoporous alumina membrane allowed relatively large amounts of enzyme to be incorporated. Yang et al. 2007 [127] immobilized urease on nanoporous alumina membranes; the immobilized enzyme served as the basis of an electrode-separated piezoelectric sensor. The urea sensor exhibited short response times, high selectivity for urea as well as long-term storage stability. La Flamme et al. (2007) [128] examined the use of nanoporous alumina and poly (ethylene glycol)-modified nanoporous alumina as membranes for immunoisolation devices. The surfaces of nanoporous alumina membranes were modified with poly (ethylene glycol) in order to resist the adhesion of blood proteins as well as immune cells; proteins and cells may block pores and reduce diffusion across an immunoisolation device membrane. One of the gains of APA arrays is that information on binding kinetics (e.g. kinase interacting with a peptide substrate and how kinase inhibitors affect such an interaction) can be obtained; something that is possibly valued to drug selection processes [129]. Similarly, surface functionalization may also permit the addition of cell-specific finding reagents and cell-capture agents. This may permit the recruitment, culture and detection of specific sorts of bacteria. These types of assays are likely to have extra roles in the presentation for microorganisms not only for industrial applications, but also in the detection of infections in medical diagnostics. Further, a recent study proposed a large-area SERS device with efficient fluorescence quenching capability of APA templates with various pore size and wall thickness as small as 15 and $36 \mathrm{~nm}$, nano-patterned SERS substrate, with excellent control and reproducibility of plasmon-polaritons generation, shows very efficient enhanced Raman signal in the presence of intrinsically fluorescent molecules such as cresyl violet, rhodamine, and green fluorescent protein [130]. This work determines that, when the nanostructures are properly designed and fabricated, Raman and fluorescence spectroscopy can be used in combination to obtain complementary molecular informations. Theoretical simulation shows excellent agreement with the experimental findings. The SERS enhancement factor ' $G$ ' is found to be $10^{3}-10^{4}$, with respect to flat gold surface when the molecules are supposed to be closely packed, with considerable fluorescence suppression, make these substrates disposable, opening the way to their large-scale and real application as a biosensor.

\subsection{CELL CULTURE}

The surface of APA nanopores can also be modified with versatile methods to tailor them for specific cell growth. In addition, nanoporous APA membranes have a low-background autofluorescence, which is advantageous for cell counting applications in particular [131]. APA membranes with diameters ranging from 13 to $150 \mathrm{~nm}$ are currently fabricated by Synkera Technologies (US), and nanoporous APA cell culture chips with up to 180000 micron-sized growth compartments are produced by Micro dish in the Netherlands. Since nano topographic features of a biomaterial such as nanoporous APA influence its interaction with biological tissues or cells $[132,133]$. A study of the growth of neuronal cell on nanoporous APA membranes is composed in table 5. Customized APA nanopores have been used in these surveys as well as commercially available alumina membranes, and different coatings and surface modifications were employed. In a study [133] Cell proliferation increased with an increase in pore diameter and was highest on substrates with $200 \mathrm{~nm}$ pores. In contrast, cell functionality was fostered on membranes with small pore diameters of around $50 \mathrm{~nm}$. This suggests that it is possible to directly influence the response of HepG2 cells to the nanoporous substrates by varying the pore size of the membranes. This proved that nanometer surface features of a biomaterial are a key component during their interactions with biological tissues or cells.

\subsection{APA MEMBRANE FOR IMMUNOISOLATION AND DRUG DELIVERY APPLICATION}

Over the past years nanoporous alumina membranes have been introduced into several drug delivery and immunoisolation applications [134]. In broad, immunoisolation is the method of protective implanted material such as biopolymer; cells or drugs release carriers from immune reactions. It can be proficient by encapsulation porous alumina semipermeable membrane. In 2002, biocapsules produced from APA have been presented by Gong et al. to encapsulate molecules of different molecular weight. Molecular diffusion characteristics from the APA capsules could be well controlled for the two model drugs fluorescein and FITC dextran by adjusting the pore size from 25 to $55 \mathrm{~nm}$ [17]. The diffusion of molecules larger than a critical size could also be prevented in this study. Using multiple anodization voltages La Flamme et al. were even able to produce APA capsules with branched pores where single branches had diameters of less than $10 \mathrm{~nm}$. In a follow up study biocapsules with pore sizes of $75 \mathrm{~nm}$ were found to be more durable than comparable polymeric immunoisolation designs [128]. These pores are big sufficient to permit smaller molecules for example glucose, oxygen and insulin to pass, however are small sufficient to hinder the passage of considerable bigger immune reactions molecules such as immunoglobulin which suggests that the APA biocapsules could be used to protect cell grafts in vivo. When pancreatic B-cell line (MIN6) were encapsulated in these APA capsules for 24 hours they exhibited good viability. Yet, the cells were spread inhomogeneously within the capsule, which might be 
because of limited nutrient access in the nanoarchitecture. When various glucose stimuli were applied to the encapsulated insulin- secreting MIN6 cells they showed a dynamic response, which will enable future encapsulation strategies for the treatment of diabetes. Like in the artificial pancreas, insulin discharging pancreatic cells is captured inside an immunoisolating device and a semipermeable membrane action as a boundary between the cells and the body [128]. The capsules have many appealing features for cellular encapsulation applications.

Nanoporous membranes offer a single method for regulating the passage level of not only proteins and additional biological molecules, but also drugs. One possible application is self-regulated drug delivery, in which passage of a captured drug is regulated based on a change in a given physiologic parameter. The functionality of the majority of these smart membranes like porous alumina is based on reversible expansion and collapse of responsive polymers integrated into the membranes that regulate fluid/molecular transport through the pores and provide a chemomechanical effect see in figure 10. In implantable drug delivery or immunisolation devices the membrane would function as a semipermeable compartment that holds the implant or dug while allowing passage of desired molecules in controlled manner. The purpose of controlled delivery systems is to administer drugs in a chosen way for more effective therapy and to eliminate the possibility of improper dosing. Surface modification, including the surface at the pore mouth, can have profound influences on the transport rate of specific drugs. Moreover, size, porosity, and membrane thickness offer an attractive route for making capsules that may be used for providing controlled release of pharmacologic agents [135]. For example; nanoporous materials are researched for use in drug eluting stents to treat coronary artery disease [136]. Recently, nanoporous inorganic membranes have been tested for sustained release of ophthalmic drugs to treat conditions related to the eye [137]. Recently, APA membranes with $20 \mathrm{~nm}$ large pores were also presented as drug carrier for the release of amoxicillin [18]. Over 5 weeks a controlled, sustained release of the model drug was observed with an antibiotic release being proportional to the square root of time. The enzyme glucose oxidase has also been encapsulated in APA membranes to develop electrochemical biosensors, which measure the enzyme activity [85]. Pore sizes in this study ranged from 30 to $80 \mathrm{~nm}$, and the outer surface of the biocapsule sensor was coated with the biopolymer chitosan to increase the enzyme stability within the capsule. When the pore diameter enhanced a larger amount of enzyme could be stored in the pores. For smaller diameters a slower response of the sensor was observed, which was slowest for a pore diameter of $40 \mathrm{~nm}$ in a $150 \mu \mathrm{m}$ thick pore. Drug loaded nanoporous APA membranes have also been used as stent coatings to prevent restenosis after coronary intervention. Wieneke et al. coated $316 \mathrm{~L}$ stainless steel coronary stents with $500 \mathrm{~nm}$ of nanoporous APA and loaded them with the immunosuppressive drug tacrolimus (FK506), which also inhibits the growth of human vascular smooth muscle cells [138,1396]. The nanoporous APA coating on its own showed good biocompatibility in the rabbit carotid artery model. Implanting drug-eluting APA stents with FK506 in the common carotid artery of New Zealand rabbits for 28 days reduced the formation of neointima scar tissue by $50 \%$ and also yielded a lower inflammatory response by inhibiting the release of pro-inflammatory cytokines. When studying the in vitro drug release of tacrolimus from APA coated stents a cumulative release was measured within the first 144 hours. After 72 hours approximately $75 \%$ of the loaded drug had been eluted $25 \%$ were still trapped in the APA nanopores [140]. These findings will be advantageous for the future development of nanoporous APA stent coatings, for which further continuing investigations on the biocompatibility and the reendothelialisation are necessary in future [138]. Antiangiogenic and antioxidant drugs were also loaded into capsules of APA membranes with $20 \mathrm{~nm}$ pore size by Orosz et al. to study their diffusion behaviour through this nanoarchitecture [141]. They cultivated human retinal endothelial cells (HREC) on the nanomembranes and exposed them to catalase, vitamin $\mathrm{C}$ and endostatin respectively. When vitamin $\mathrm{C}$ diffused through the membrane it was found to modulate the HREC's ability to survive and grow. The antiangiogenic molecule endostatin could block the growth of HREC after it diffused through the APA nanopores. Moreover, diffused catalase was able to defend the HREC culture on the APA membrane from the cytotoxic effects of hydrogen peroxide. Thus, implantable biocapsules from APA can also be applied in future to deliver various drugs of ophthalmic interest.

\subsection{ANODIC POROUS ALUMINA IN FUNCTIONAL PROTEOMICS AND NANOCRSTALLOGRAPHY}

As alumina oxide $\left(\mathrm{Al}_{2} \mathrm{O}_{3}\right)$ is inert towards the macromolecules. The stability and dynamic range of microarrays printed with purified protein have hampered their widespread adoption. Moreover, APA offer many qualities like high surface area expansion, better microfluidic properties, flexibility in porous dimension and confinement possessions as a mean for selectivity and maximization of light emission. The most common difficult is still remaining on planar microarray supports is spot concentration and accumulation, which leads to non-uniform intensity profiles; in that respect porous materials with improved microfluidic properties, can be solution. On the other hand, the high throughput protein crystallography including this using nano volume allows to considerably reducing amount of protein used for crystallization trail. Normally, crystallization on the 
porous support needs even lesser amount of protein in contrast classical in volume crystallization [142]. This principal can be applied for the APA-cell free combined technique, but with considerable more effect on the crystallization process itself. Taking an alternate approach, the Nucleic Acid Programmable Protein Array (NAPPA) is constructed by spotting protein-encoding plasmid DNA at high density, in addressable way, on an array surface. The Nucleic acid-Programmable Protein Array (NAPPA) is a novel protein microarray. NAPPA eliminates the need of purified proteins by spotting plasmid DNA instead of proteins. All the genes on the array are then simultaneously transcribed/translated in a cell-free system; the resulting proteins are immobilized in situ. Label-free protein-protein interactions were recently monitored using self-assembling protein NAPPA microarrays and anodic porous alumina [143] in an attempt to monitor the proteome alteration associated with cell proliferation, differentiation and neoplastic transformation. As such, the NAPPA platform offers a unique and viable alternative that circumvents many of the inherent limitations of spotted protein arrays, enabling diverse functional protein studies including protein-small molecule, protein-protein, antigen-antibody, and protein-nucleic acid interactions. Moreover, Label-free NAPPA technology, in combination with protein nanobiocrystallography and its possible future development using anodic porous alumina along with a cell-free expression system as specified in [144] and, appear to form a single approach capable of effectively solving the numerous problems still present in medical diagnosis and therapy [145].

\section{Conclusion And Future Perspective}

Diverse and inventive minds have seized upon the properties of APA and exploited this material in biomedical applications as wide-ranging as molecular separations, high throughput screening, drug delivery and sensors. The structural properties of APA have been transferred to other materials, as inverse structures (nanotubes and nanowires) or by replicating the pore pattern by using the APA as a shadow mask. Improvements in the basic structure of APA have resulted in more regular pores. Alterations in the surface properties of APA have been achieved by chemical functionalization. Functionalization has allowed fine-tuning of basic surface charge and hydrophobicity, but also the specific capture of biomolecules, facilitating highly multiplexed assays. Despite intense interest, we still do not completely understand the self-ordering process that anodization brings to aluminum. Therefore, it is necessary to investigate this phenomenon more completely, which should, in turn, unlock further advances in controlling and extending the range of APA variants available. Surface chemistry, to date, generally functionalizes APA in limited ways. The use of surface modification technique to improve the function of nonporous alumina membrane is reviewed. Even the extensive research carried out in fabrication, characterization and modification of nanoporous alumina membrane materials, there are still several challenges that must be overcome in order to create synthetic nanopore systems that behave similarly to their biological counterparts. Appropriate control of the pore size, pore charge, ionic strength and $\mathrm{pH}$ can tune the protein transport through nanoporous alumina membrane membranes for use as mass transfer gates. Existing commercial membranes offer inexpensive means to separate bioanalytical applications such as large-scale preconcentration. On the other hand, development of truly nanoscale devices calls for more controlled pore architecture and the ability to sort and dispense molecules very precisely. Pore geometry, biocompatibility, and biofouling resistance are central issues for APA membranes that are used as interfaces in implantable devices. The effort to find suitable nanoporous interfaces for the diverse biomedical applications will rely on an interdisciplinary approach involving materials science, chemistry, biology, and engineering. Many challenges lie ahead when developing nonfouling nanoporous APA membrane that is suitable for longterm in vivo biomedical applications. Surface modification by coating nanoporous membranes with inorganic as well as organic materials is currently being explored. While techniques such as modification with grafted polymers and self-assembled polymers have given promising results during in vitro testing, in vivo testing will be conducted in the future. An example for such a smart membrane is pore surface modification with responsive polymers that undergo a conformational transition in response to stimuli such as $\mathrm{pH},[146,147]$ temperature, [148] and ion concentration [149]. A significant challenge is to construct composite nanoporous membranes that respond to multiple stimuli. Such novel systems can be used in nano/microscale chips for programmable drug delivery and biomolecular analysis. Several chemistries exist but generally the same modification is made across a piece of this material. Where different biomolecules are recruited to different areas (e.g. in fabricating a microarray with different biomolecules in different spots) then this is usually done by printing and a secondary conjugation. In the future we may expect higher resolution and more versatile surface chemistries. Two trends in detection methods are supportive of multiplexed assays on APA. The principal is linked to the benefits that the material passes in relations of optical imaging procedures (SERS, optical wave guides). If these refined and influential procedures can be taken to the market then this opens up main types of reagent free imaging. Furthermore, progresses in modest and economy lighting procedures, mainly LEDs [150], and the development of new detection reagents (nanoparticles) should permit fluorescence-based detection methods to rise in power. Developments in imaging, for example low cost digital data capture, USB microscopes, direct detection of cell 
autofluorescence using CCD chips [151] can be likely to aid wider usage. The cut in LED prices and price-perpixel of digital data capture supports the growing lessening of microbial culture with cheap and point-of-testing and/or online read-out means, an objective that has been defined as tele microbiology [152]. One logical, but not completely cool, step would be assays that mix elements from both technology streams. This would consent a mixture of phenotyping and genotyping, or identification of a target organism joined with an analysis of whether it is feasible and what it is proficient of (e.g. pathogenicity or carcogenicity). This objective could be succeeded on APA systems by capturing organisms based around their surface properties (e.g. an antibody) followed by culture; or the reverse - culture and molecular analysis. Materials can have a major impact on biotechnology. For example, relatively simple and inexpensive plastics have transformed many aspects including cell growth and high throughput screening through disposables, such as the multiwell plate and the disposable Petri dish.

We are only just learning to leverage the potential of nanoporous materials in biology, but it is our expectation that such materials, including APA, will have a significant impact too.

Haynes, C.L. and Van Duyne, R.P. (2003) Plasmon-sampled surface enhanced Raman excitation spectroscopy. J. Phys. Chem. B $107,7426-7433$

[2] Landskron, K. et al. (2003) Periodic mesoporous organosilicas containing interconnected [Si (CH2)] 3 rings. Science 302, 266269

[3] Anne Julbe, David Farrusseng,Christian Guizard, Porous ceramic membranes for catalytic reactors overview and new ideas Journal of membrane science Volumes 181,Issue1, Pages 3-20

[4] Tong, H.D. et al. (2004) Silicon nitride nanosieve membrane. Nano Lett.4, 283-287

[5] Osmanbeyoglu, H.U. et al. (2009) Thin alumina nanoporous membranes for similar size biomolecule separation. J. Membr. Sci.343, $1-6$

[6] Striemer, C.C. et al. (2007) Charge- and size-based separation of macromolecules using ultrathin silicon membranes. Nature 445, 749-753

[7] Vlassiouk, I. et al. (2004) 'Direct' detection and separation of DNA using nanoporous alumina filters. Langmuir 20, 9913-9915

[8] Haes, A.J. et al. (2004), A nanoscale optical biosensor: the long range distance dependence of the localized surface plasmon resonance of noble metal nanoparticles. J. Phys. Chem. B 108, 109-116

[9] Venkatesan, B.M. et al. (2009), Highly sensitive, mechanically stable nanopore sensors for DNA analysis. Adv. Mater. 21, 27712776

[10] VGrasso V Lambertini, P Ghisellini, F Valerio, E Stura, P Perlo and C Nicolini, Nanostructuring of a porous alumina matrix for a biomolecular microarray Nanotechnology 17 (2006) 795-798

[11] Howorka, S. et al. (2001) Sequence-specific detection of individual DNA strands using engineered nanopores. Nat. Biotechnol. $19,636-639$

[12] Dimitrov, V. et al. (2010) Nanopores in solid-state membranes engineered for single molecule detection. Nanotechnology 21, 111

[13] Gu, L.Q. and Shim, J.W. (2010) Single molecule sensing by nanopores and nanopore devices. Analyst 135, 441-451

[14] Poinern GEJ, Shackleton R, Mamum SI, Fawcett D. Significance of novel bioinorganic aluminum oxide nanoscaffolds for promoting cellular response. Nano Sci Appl 2011; 4:11-24

[15] Bolton J, Bailey TS, Rzayev J. Large pore size nanoporous materials from the selfassembly of asymmetric bottlebrush blocks copolymers. Nanoletters 2011. Doi:10.1021/am2000533.

[16] Han, J.Y. et al. (2008) Molecular sieving using nanofilters: past, present and future. Lab. Chip 8, 23-33

[17] Keller, F.; Hunter, M. S.; Robinson, D. L. J. Electrochem. Soc. 1953, 100, 411.

[18] Diggle, J. W.; Downie, T. C.; Goulding, C. W. Chem. Rev. 1969, 69, 365.

[19] Thompson, G. E. Thin Solid Films 1997, 297, 192.

[20] Keller, F.; Hunter, M. S.; Robinson, D. L. J. Electrochem. Soc.1953, 100, 411,

[21] Furneaux, R. C.; Rigby, W. R.; Davidson, A. P. Nature 1989,337, 147.

[22] Martin, C. R. Science 1994, 266, 1961.

[23] Li, A.-P.; Mu" ller, F.; Birner, A.; Nielsch, K.; Go"sele, U. Adv. Mater. 1999, 11, 483.

[24] Mu" ller, F.; Birner, A.; Schilling, J.; Li, A.-P.; Nielsch, K.; Go“sele, U.; Lihmann, V. Microsyst. Technol. $2002,8,7$.

[25] Rurack, K. and Martinez-Manez, R. (2010), The Supramolecular Chemistry of Organic-Inorganic Hybrid Materials, John Wiley \& Sons

[26] C. T. Kresge,M.E.Leonowicz,W. J.Roth, J. C. Vartuli and J. S. Beck, Nature, 1992, 359, 710.

[27] D. Zhao, J. Feng, Q. Huo, N. Melosh, G. H. Fredrickson, B. F. Chmelka and G. D. Stucky, Science, 1998, $279,548$.

[28] G. J. de A. A. Soler-Illia, C. Sanchez, B. Lebeau and J. Patarin, Chem. Rev., 2002, 102, 4093.

[29] J.Cejka, Appl. Catal., A, 2003, 254, 327.

[30] G. E. Thompson, Thin Solid Films 1997, 297, 192.

[31] Nielsch K, Choi J, Schwirn K, Wehrspohn RB, Gosele U. Self-ordering regimes of porous alumina: The $10 \%$ porosity rule. Nanoletters 2002; 2:677-80.

[32] G. E. Thompson, G. C. Wood, Nature 1981, 290, 230.

[33] T. Iijima, S. Kato, R. Ikeda, S. Ohki, G. Kido, M. Tansho, T. Shimizu, Chem. Lett. 2005, 34, 1286

[34] Landskron, K. et al. (2003) Periodic mesoporous organosilicas containing interconnected [Si (CH2)] 3 rings. Science 302, 266269

[35] Chu, K.L. et al. (2006) An improved miniature direct formic acid fuel cell based on nanoporous silicon for portable power generation. J. Electrochem. Soc. 153, A1562-A1567

[36] Tong, H.D. et al. (2004) Silicon nitride nanosieve membrane. Nano Lett. 4, 283-287

[37] Osmanbeyoglu, H.U. et al. (2009) Thin alumina nanoporous membranes for similar size biomolecule separation. J. Membr. Sci. $343,1-6$

[38] Striemer, C.C. et al. (2007) Charge- and size-based separation of macromolecules using ultrathin silicon membranes. Nature 445, 749-753

[39] Vlassiouk, I. et al. (2004) 'Direct' detection and separation of DNA using nanoporous alumina filters. Langmuir 20, 9913-9915 
[40] Chem. common 2005, 1986-1987, Indian Journal of Science and Technology, Vol. 3 No. 10 (Oct 2010).

[41] Indian Journal of Science and Technology, Vol. 3 No. 10 (Oct 2010)).

[42] Haes, A.J. et al. (2004) A nanoscale optical biosensor: the long range distance dependence of the localized surface plasmon resonance of noble metal nanoparticles. J. Phys. Chem. B 108, 109-116

[43] Masuda H, Satoh M. Fabrication of gold nanodot array using anodic porous alumina as an evaporation mask. Jpn J Appl Phys 2 Lett 1996; 35:L126-9.

[44] Masuda H, Yamada H, Satoh M, Asoh H, Nakao M, Tamamura T. Highly ordered nanochannel-array architecture in anodic alumina. Appl Phys Lett 1997;71:2770-2.)

[45] Li FY, Zhang L, Metzger RM. On the growth of highly ordered pores in anodized aluminum oxide. Chem Mater 1998;10(9):2470-80.

[46] Su ZX, Zhou WZ. Formation mechanism of porous anodic aluminium and titanium oxides. Adv Mater 2008;20(19):3663-7.

[47] Despic A, Parkhutik VP. Electrochemistry of aluminum in aqueous solutions and physics of its anodic oxide. In: Bokris JO, White RE, Conway BE.

[48] Valand T, Heusler KE. Reactions at the oxide-electrolyte interface of anodic oxide films on aluminum. J Electroanal Chem $1983 ; 149(1-2): 71-82$.

[49] Su ZX, Hahner G, Zhou WZ. Investigation of the pore formation in anodic aluminium oxide. J Mater Chem 2008;18(47):578795.

Plumb RC. Studies of the anodic behaviour of aluminium. II. Coulometry of barrier layer production. J Electrochem Soc 1958; 105(9):498-502.

[51] Dorsey, Jr. GA. The characterization of anodic aluminas Composition of films from acid electrolytes. J Electrochem Soc 1966; 113(2):169-72.

[52] Thompson GE, Wood GC. Porous anodic film formation on aluminium. Nature 1981;290(5803):230-2.

[53] Siejka J, Ortega C. An O18 study of field-assisted pore formation in compact anodic oxide films on aluminum. J Electrochem Soc $1977 ; 124(6): 883-91$.

[54] J. Electochem. Soc. 148, B152 (2001)

[55] Book, chapter 3, highly Ordered Nanohole Arrays in Anodic Porous Alumina

[56] Qiu T, Jiang J, Zhang W, Lang X, Yu X, Chu PK. High-sensitivity and stable cellular fluorescence imaging by patterned silver nanocap arrays. ACS Appl Mater Interface 2010; 2:2465-70.

[57] M. Salerno, N. Patra, R. Cingolani, Nanoscale Res. Lett. 4 (2009) 865-872.

[58]. G. Das N. Patra A. Gopalakrishanan R. Proietti Zaccaria A. Toma S. Thorat E. Di Fabrizio , A. Diaspro M. Salerno, Microelectronic Engineering 97 (2012) 383-3860

[ 59] Masuda H, Fukuda K. Ordered metal nanohole arrays made by a 2-step replication of honeycomb structures of anodic alumina. Science $1995 ; 268: 1466-8$.

[60] Bolton J, Bailey TS, Rzayev J. Large pore size nanoporous materials from the selfassemblyof asymmetric bottlebrush block copolymers. Nanoletters 2011. doi: 10.1021/am2000533.

[61] Ono S, Saito M, Ishiguro M, Asoh H. Controlling factor of self-ordering of anodic porous alumina. J Electrochem Soc 2004; 151:B473-8.

[62] Asoh H, Nishio K, Nakao M, Tamamura T, Masuda H. Conditions for fabrication of ideally ordered anodic porous alumina using pretextured Al. J Electrochem Soc 2001;148:B152-6.

[63] Lee W, Ji R, Gosele U, Nielsch K. Fast fabrication of long-range ordered porous alumina membranes by hard anodization. Nat Mater 2006; 5:741-7.

[64] Lee W. The anodization of aluminium for nanotechnology applications. J Metall 2010; 62:57-63.

[65] Li DD, Zhao LA, Jiang CH, Lu JG. Formation of anodic aluminum oxide with serrated nanochannels. Nano Lett 2010; 10:276671 .

[66] Kant K, Low SP, Marshal A, Shapter JG, Losic D. Nanopore gradients on porous aluminium oxide generated by non-uniform anodization of aluminium. ACS Appl Mater Interfaces 2010; 2:3447-54.

[67] Thormann A, Teuscher N, Pfannmoller M, Rothe U, Heilmann A. Nanoporous aluminiumoxide membranes for filtration and biofunctionalalization. Small 2007; 6:1032-40.

[68] Mateo JN, Kulkarni SS, Das L, Bandyopadhyay S, Tepper GC, Wynne KJ, et al. Wetting behavior of polymer coated nanoporous anodic alumina films: transition from super-hydrophilicity to super hydrophobicity. Nanotechnology 2011; 22. doi: 10.1088/0957-4484/22/3/035703.

[69] Wang M, Meng G, Huang Q, Li M, Li Z, Tang C. Fluorescence detection of trace PCB101 based on PITC immobilized on porous AAO membrane. Analyst 2011;136:278-81

[70] Chen YF, Hu YH, Chou YI, Lai SM, Wang CC. Surface modification of nano-porous anodic alumina membranes and its use in electroosmotic flow. Sensors Actuators B-Chem 2010; 145:575-82.

[71] Mutalib A, Jani M, Anglin EJ, McInnes SJP, Losic D, Shapter JG, et al. Nanoporous anodic aluminium oxide membranes with layered surface chemistry. Chem Commun 2009. doi:10.1039/b901745c.

[72] Szczepanski V, Vlassiouk I, Smirnov S. Stability of silane modifiers on alumina nanoporous membranes. J Membr Sci 2006; 281:587-91.

[73] Javid A, Gonzalez SO, Simanek EE, Ford DM. Nanocomposite membranes of chemisorbed and physisorbed molecules on porous alumina for environmentally important separations. J Membr Sci 2006; 275:255-60.

[74] Lee SB, Mitchell DT, Trofin L, Nevanen TK, Soderlund H, Martin CR. Antibody-based bionanotubemembranes for enantiomeric drug separations. Science 2002; 296:2198-200.

[75] Milka P, Krest I, Keusgen M. Immobilization of alliinase on porous alumium oxide. Biotechnol Bioeng 2000; 69:344-8.

[76] Matsumoto F, Nishio K, Masuda H. Flow-through-type DNA array based on ideally ordered anodic porous alumina substrate. Adv Mater 2004; 16:23-4.

[77] Enrico Stura, Debora Bruzzese, Federica Valerio, Valentina Grasso, Pietro Perlo, Claudio Nicolini, Anodic porous alumina as mechanical stability enhancer for LDL-cholesterol sensitive electrodes Biosensors and Bioelectronics 23 (2007) 655-660

[78] Ko H, Tsukruk VV. Nanoparticle-decorated nanocanals for surface-enhanced Raman scattering. Small 2008; 4:1980-4.

[79] Losic D, Cole MA, Dollman B, Vasilev K, Griesser HJ. Surface modifications of nanoporous alumina membranes by plasma polymerization. Nanotechnology 2008; 19:25704.

[80] Pistorius A,Willershausen B. Biocompatibility of dental materials in two human cell lines. Eur J Med Res 2002, 7:81-88.

[81] Ulman, A. (1991),An Introduction to Ultrathin Organic Films, Academic Press 

membranes. Langmuir 16, 2401-2404

[83] S. Sharma and T.A. Desai, Journal of Nanoscience and Nanotechnology, 5 (2005), pp. 235-243

[84] Chang CS, Suen SY. Modifications of porous alumina membranes with n-alkanoic acids and their application in protein adsorption. J Membr Sci 2006; 275:70-81.

[85] Liakos IL, Newman RC, McAlpine E, Alexander MR. Comparative study of self-assembly of a range of monofunctional aliphatic molecules on magnetron-sputtered aluminium. Surf Interface Anal 2004;36:347-54.

[86] Oberg K, Persson P, Shchukarev A, Eliasson B. Comparison of monolayer films of stearic acid and methyl stearate on an Al2O3 surface. Thin Solid Films 2001; 397:102-8.

[87] Yildirim O, Gang T, Kinge S, van der Wiel WG, Reinhoudt DN, Blank DHA, Rijnders G, Huskens J. Monolayer-directed assembly and magnetic properties of FePt nanoparticles on patterned aluminum oxide. Int J Mol Sci 2010;11:1162-79.

[88] Koutsioubas AG, Spiliopoulos N, Anastassopoulos D, Vradis AA, Priftis GD. Nanoporous alumina enhanced surface plasmon resonance sensors. J Appl Phys 2008:103.

[89] ter Maat, J., Regeling, R., Ingham, C.J., Weijers, C.A.G.M., Giesbers, M., de Vos, W.M., Zuilhof, H. Organic modification of porous anodic alumina with terminal alkynes and its biofunctionalization. Langmuir; submitted for publication.

[90] Park BG, Lee W, Kim JS, Lee KB. Superhydrophobic fabrication of anodic aluminum oxide with durable and pitch-controlled nanostructure. Colloids Surf A Physicochem Eng Aspects 2010; 370:15-9.

[91] Tasaltin el al, Nanoscale Research Letter 2011, 6)

[92] Popat KC, Mor G, Grimes CA, Desai TA. Surface modification of nanoporous alumina surfaces with poly(ethylene glycol). Langmuir 2004; 20:8035-41.

[93] Yeu S, Lunn JD, Rangel HM, Shantz DF. The effect of surface modifications on protein microfiltration properties of Anopore membranes. J Membr Sci 2009; 327:108-17.

[94] Narayan RJ, Jin C, Menegazzo N, Mizaikoff B, Gerhardt RA, et al. Nanoporous hard carbon membranes for medical applications. J Nanosci Nanotech 2007, 7:1486-2493.

[95] S. L. Pan and L. J. Rothberg, Nano Lett., 2003, 3, 811-814.

[96] K. H. A. Lau, L. S. Tan, K. Tamada, M. S. Sander and W. Knoll, J. Phys. Chem. B, 2004, 108, 10812-10818.

[97] S. D. Alvarez, C. P. Li, C. E. Chiang, I. K. Schuller and M. J. Sailor, ACS Nano, 2009, 3, 3301-3307.

[98] Roman Dronov, a Andrew Jane, a Joseph G. Shapter, a Alastair Hodgesb and Nicolas H. Voelcker*a Nanoscale, 2011, 3, 3109, Nanoscale 02/2011; 3(8):3109-14. DOI: 10.1039/c0nr00897d

[99] Moskovits M. Spot the hotspot. Nature 2011;469:307-8

[100] Schierhorn M, Lee SJ, Boettcher SW, Stucky GD, Moskovits M. Metal-silica hybrid nanostructures for surface-enhanced Raman spectroscopy. Adv Mater 2006; 18: 2829-32.

[101] Ji N, Ruan WD, Wang CX, Lu ZC, Zhao B. Fabrication of silver decorated anodic aluminium oxide substrate and its optical properties on surface-enhanced Raman scattering and thin film interference. Langmuir 2009;25:11869-73.

[102] Ko H, Tsukruk VV. Nanoparticle-decorated nanocanals for surface-enhanced Raman scattering. Small 2008;4:1980-4.

[103] Ko H, Chang S, Tsukruk VV. Porous substrates for label-free molecular level detection of nonresonant organic molecules. ACS Nano 2009;3:181-8.

[104] Lu ZC, Ruan WD, Yang JX, Xu WQ, Zhao C, Zhao B. Deposition of Ag nanoparticles on porous anodic alumina for surface enhanced Raman scattering substrate. J Raman Spectrosc 2009;40:112-6.

[105] Choi D, Choi Y, Hong S, Kang T, Lee LP. Self-organized hexagonal-nanopore SERS array. Small 2010;6:1741-4.

[106] Qiu T, Zhang WJ, Lang XZ, Zhou YJ, Cui TJ, Chu PK. Controlled assembly of highly Ramanenhancing silver nanocap arrays templated by porous anodic alumina membranes. Small 2009;5:2333-7.

[107] G. Das N. Patra A. Gopalakrishanan R. Proietti Zaccaria A. Toma S. Thorat E. Di Fabrizio , A. Diaspro M. Salerno, Microelectronic Engineering 97 (2012) 383-3860

[108] L. Leoni, A. Boiarski, and T.A. Desai, Biomedical Microdevices, 4 (2002), pp. 131-139.

[109] E.N. Gatimu, J.V. Sweedler, and P.W. Bohn, Analyst, 131 (2006), pp. 705-709.

[110] Z. Huang et al., Journal of Medical Devices, 1 (2007), pp. 79-83.

[111] F. Martin et al., Journal of Controlled Release, 102 (2005), pp. 123-133.

[112] Hoess A, Thormann A, Friedmann A, Heilmann A. 2012. Self-supporting nanoporous alumina Membranes as substrates for hepatic cell cultures. J Biomed Mater Res Part A 2012).

[113 ] Han J. In: Di Ventra M, Evoy S, Heflin JR eds. Introduction to Nanoscale Science and Technology. New York: Springer; 2004

[114 ] Ghosh R. Protein Bioseparation Using Ultrafiltration: Theory, Applications andNew Developments. London: Imperial College Press; 2002

[115 ] T. Tsuru, Separation and Purification Methods, 30 (2001), pp. 191-200.

[116 ] R.A. Mason and H.K. Lonsdale, Journal of Membrane Science, 51 (1990), pp. 1-81.

[117 ] Thin alumina nanoporous membranes for similar size biomolecule separation, Journal of Membrane Science 343 (2009) 1-6

[118 ] T.M. Squires, S.R. Quake, Microfluidics: fluid physics at the nanoliter scale, Rev.Mod. Phys. 77 (2005) 1008.

[119] Chun, K.Y. and Stroeve, P. (2001) External control of ion transport in nanoporous membranes with surfaces modified with selfassembled monolayers. Langmuir 17, 5271-5275

[120 ] Chun, K.Y. et al. (2006) Protein transport through gold-coated, charged nanopores: effects of applied voltage. Chem. Phys. Lett. $418,561-564$

[121] Ku, J.R. et al. (2007) $\mathrm{pH}$ and ionic strength effects on amino acid transport through Au-nanotubule membranes charged with selfassembled monolayers. J. Phys. Chem. C 111, 2965-2973

[122 ] Jani AMM, Anglin EJ, McInnes SJP, Losic D, Shapter JG, Voelcker NH. Nanoporous anodic aluminium oxide membranes with layered surface chemistry. Chem Commun 2009:3062-4.

[123 ] Jani AMM, Kempson IM, Losic D, Voelcker NH. Dressing in layers: layering surface functionalities in nanoporous aluminum oxide membranes. Angew Chem Int Ed 2010; 49:7933-7.

[124] Trivinho-Strixino F, Guerreiro HA, Gomes CS, Pereira EC, Guimaraes FEG. Active waveguide effects from porous anodic alumina: an optical sensor proposition. Appl Phys Lett 2010. 97.011902.

[125 ] Wu Y, de Kievit P, Vahlkamp L, Pijnenburg D, Smit M, Dankers M, et al. Quantitative assessment of a novel flow-through porous microarray for the rapid analysis of gene expression profiles. Nucleic Acids Res 2004; 32. doi:10.1093/nar/gbh118.

[126] Madara , s, M. B. \& Buck, R. P. 1996 Miniaturized biosensors employing electropolymerized permselective films and their use for creatinine assays in human serum. Anal. Chem. 68, 3832-3839. (doi:10.1021/ac960239r)

[127 ] Yang et al. (2007) 
[128] La Flamme KE, Popat KC, Leoni L, Markiewicz E, La Tempa TJ, Roman BB, Grimes CA, Desai TA., Biocompatibility of nanoporous alumina membranes for immunoisolation, Biomaterials. 2007 Jun;28(16):2638-45. Epub 2007 Mar 1

[129] Vivanco I, Rohle D, Versele M, Iwanami A, Kuga D, Oldrini B, et al. The phosphatase and tensin homologue regulates epidemal growth factor receptor (EGFR) inhibitor response by targeting EGFR for degradation. Proc Natl Acad Sci 2010; 107:6459-64.

[130] Gobind Das, Niranjan Patra, Anisha Gopalakrishnan, Remo Proietti Zaccaria, Andrea Toma, Sanjay Thorat, Enzo Di Fabrizio, Alberto Diaspro and Marco Salerno, Fabrication of large-area ordered and reproducible nanostructures for SERS biosensor application Analyst, 2012, 137, 1785

[131 ] S. E. Jones, S. A. Ditner, C. Freeman, C. J. Whitaker, and M. A. Lock, "Comparison of a new inorganic membrane filter (Anopore) with a track-etched polycarbonate membrane filter (Nuclepore) for direct counting of bacteria," Applied and Environmental Microbiology, vol. 55, no. 2, pp. 529-530, 1989.

[132 ] G. E. J. Poinern, R. Shackleton, S. I. Mamun, and D. Fawcett, "Significance of novel bioinorganic anodic aluminum oxide nanoscaffolds for promoting cellular response," Nanotechnology, Science and Applications, vol. 4, no. 1, pp. 11-24, 2011.

[ 133 ] A.Hoess, A.Thormann, A. Friedmann, andA.Heilmann, "Selfsupporting nanoporous alumina membranes as substrates for hepatic cell cultures," Journal of Biomedical Materials Research Part A, vol. 100, no. 9, pp. 2230-2238, 2012.

[134] Gultepe, E., et al., Nanoporous inorganic membranes or coatings for sustained drug delivery in implantable devices. Advanced Drug Delivery Reviews, 2010. 62(3): p. 305-315.

[135] Desai TA, Sharma S, Walczak RJ, Boiarski A, CohenM, Shapiro J, West T, Melnik K, Cosentino C, Sinha PM, Ferrari M. Nanoporous implants for controlled drug delivery. In: Desai TA, Bhatia S eds. BioMEMS and Biomedical Nanotechnology Volume III TherapeuticMicro/Nanotechnology. New York: Springer, 2007.

[136 ] Nanoporous membranes for medical and biological applicationsWIREs Nanomedicine and Nanobiotechnology, Volume 1, September/October 2009

[137 ] Orosz KE, Gupta S, Hassink M, Abdel-Rahman M, Moldovan L, et al. Delivery of antiangiogenic and antioxidant drugs of ophthalmic interest through a nanoporous inorganic filter. Mol Vis 2004, 10:555-565.

[138] Wieneke, H., et al., Synergistic effects of a novel nanoporous stent coating and tacrolimus on intima proliferation in rabbits. Catheterization and Cardiovascular Interventions, 2003. 60(3): p. 399-407.

[139] Wieneke, H., et al., Synergistic effects of a novel nanoporous stent coating and tacrolimus on intima proliferation in rabbits. European Heart Journal, 2002. 23: p. 692-692.

[140] Wieneke, H., et al., Synergistic effects of a novel nanoporous stent coating and tacrolimus on intima proliferation in rabbits. Catheter Cardiovasc Interv, 2003. 60(3): p. 399-407.

[141] Orosz, K., et al., Delivery of antiangiogenic and antioxidant drugs of ophthalmic interest through a nanoporous inorganic filter. Molecular Vision, 2004. 10(68): p. 555-565.

[142] (Chayen et al.ss 2003).

[143] Nicolini \& Pechkova, Nanoproteomics for nanomedicine, Nanomedicine (2010) 5(5), 677-682

[144] Stura E, Larosa C, Bezerra Correia Terencio T et al.: Label-free NAPPA: anodic porous alumina. In: Functional Proteomics and Nanotechnology-Based Microarrays (Volume 2). Nicolini C, LaBaer J (Eds). Pan Stanford Series on Nanobiotechnology, London-New York-Singapore, 95-108 (2010).

[145] Pechkova E, Chong R, Tripathi S, Nicolini C: Cell free expression and APA for NAPPA and protein nanocrystallography. In: Functional Proteomics and Nanotechnology-Based Microarrays (Volume 2). Nicolini C, LaBaer J (Eds). Pan Stanford Series on Nanobiotechnology, London-New York- Singapore, 121-147 (2010).

[146] Mika M, Childs RF, Dickson JM. Chemical valves based on poly(4-vinylpyridine)-filled microporousmembranes. J Memb Sci 1999, 153(1):45-56.

[147] Adiga SP, Brenner DW. Toward designing smart nanovalves: modeling of flow control through nanopores via the helix-coil transition of grafted polypeptide chains. Macromolecules 2007, 40(4):1342-1348.

[148] $\quad \mathrm{A}^{\circ}$ kerman S, Viinikka P, Svarfvar B, Putkonen K, J "arvinen K, et al. Drug permeation through a temperature-sensitive poly(Nisopropylacrylamide) grafted poly(vinylidene fluoride) membrane. Int J Pharma 1998, 164:29-36.

[149] Ito Y, Park YS. Signal-responsive gating of porous membranes by polymer brushes. Polym Adv Technol 2000, 11(3):136-144

[150] Albeanu DF, Soucy E, Sato TF, Meister M, Murt VN. PLoS One 2008;3. doi:10.1371/ journal.pone.0004016.

[151] London R, Schwedock J, Sage A, Valley H, Meadows J, Waddington M, et al. An automated system for rapid non-destructive enumeration of growing microbe. PLoS One 2010; 5. doi:10.1371/journal.pone.0008609.

[152] Scheid P, Lam DM, Thömmes A, Zöller L. Telemicrobiology: a novel telemedicine capability for mission support in the field of infectious medicine. Telemed e-Health 2007;13:108-17.

Table and Figure of Paper

Table 1: Typical Membrane properties and parameters

\begin{tabular}{|l|l|}
\hline Property & Parameters \\
\hline Distribution & Hexagonal \\
\hline Pore Diameter & $10-200 \mathrm{~nm}$ \\
\hline Pore Type & Narrow Dispersed \\
\hline Pore Length & About $60 \mu \mathrm{m}$ \\
\hline Pore Density & $10^{-8}-10^{-11} \mathrm{~cm}-1$ \\
\hline Film Thickness & 0.1 to $300 \mathrm{~nm}$ \\
\hline
\end{tabular}

Table 2: Different Type of Fabrication Method

\begin{tabular}{|l|l|l|l|l|}
\hline Fabrication method & Pore Morphology & Uniformity & Scalability & Cost \\
\hline Anodization & Ordered & Good & Fair & High \\
\hline Sol- Gel & Tortuous & Fair & Fair & low \\
\hline Micro Fabrication Technique & Ordered & Good & Good & high \\
\hline
\end{tabular}




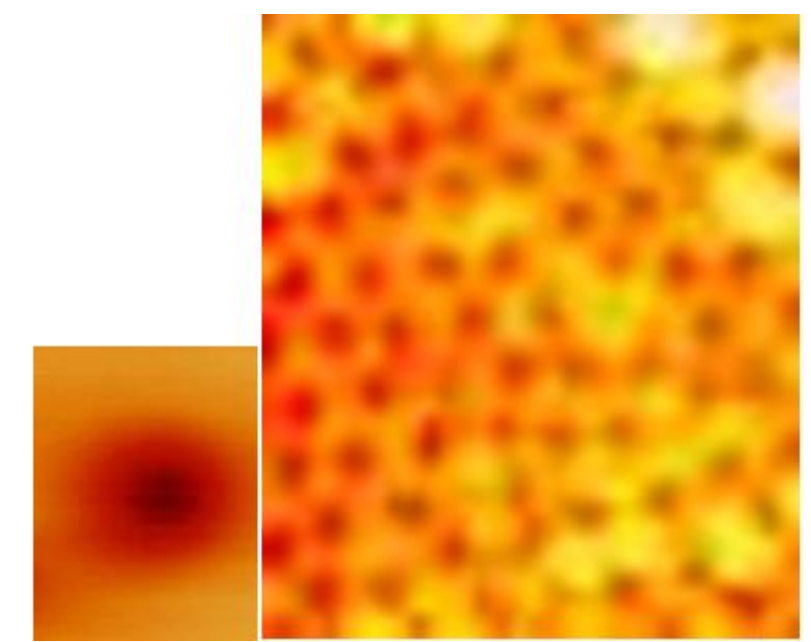

Figure: 1 Typical structure of anodic porous membrane (APA) Membrane

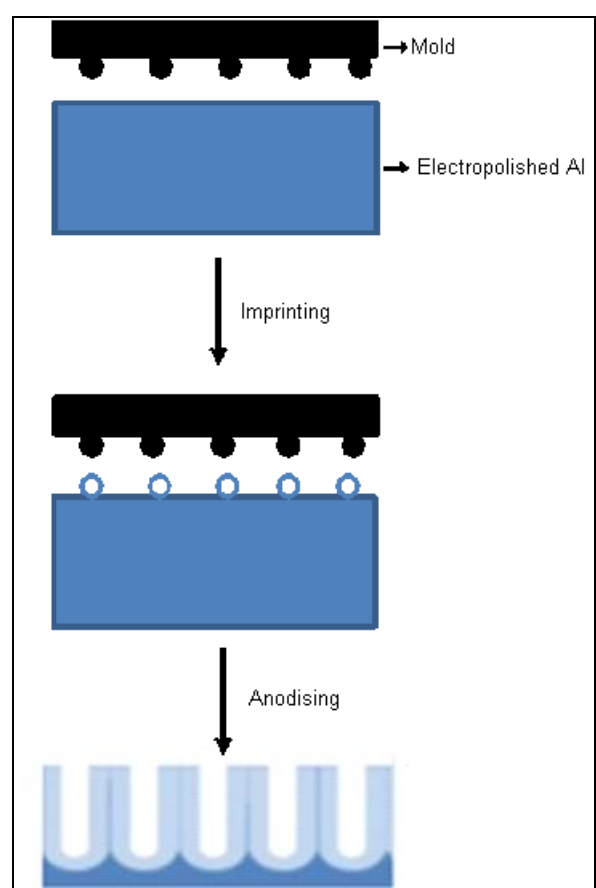

Figure 2: Schematic diagram of fabrication of ideally ordered porous alumina using an imprint stamp.

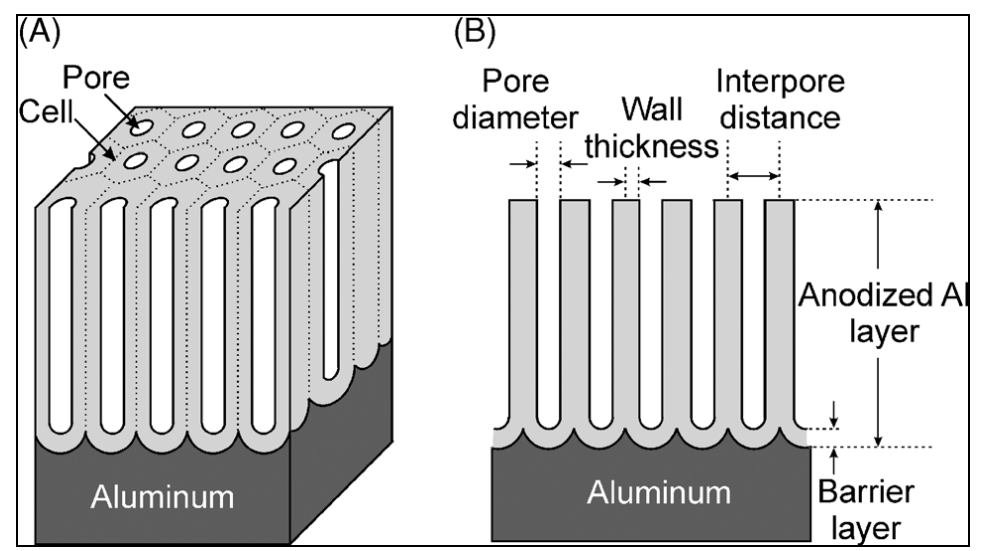

Figure: 3 High-ordered nanostructures are often characterized by given parameters. (Reprinted with permission from Ref. [Book: Nanostructured Materials in Electrochemistry. ISBN: 978-3-527-31876-6,Chapter : Highly Ordered Anodic Porous Alumina Formation by Self-Organized Anodizing, By Grzegorz D. Sulka, Edited by Ali Eftekhari, Copyright_ 2008 WILEY-VCH Verlag GmbH \& Co. KGaA, Weinheim] 


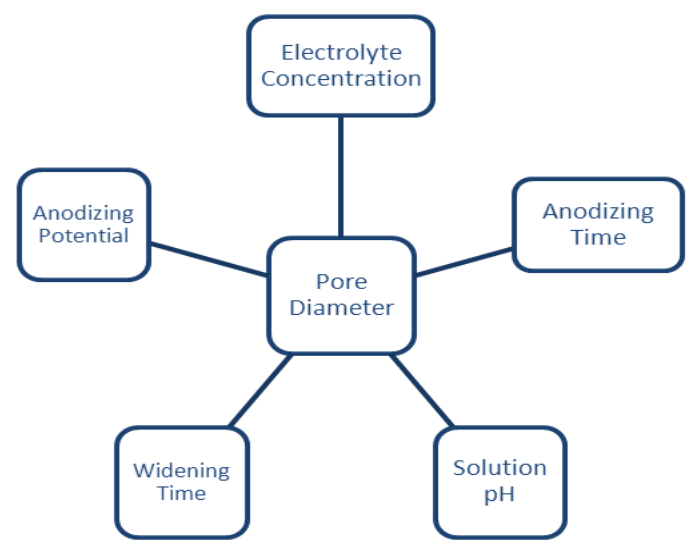

Figure 4: Parameters influence on the pore diameter of nananostructure formed by anodization of aluminum at potentiostatic system.

\begin{tabular}{|l|l|l|l|l|l|l|}
\hline Electrolyte & Potential & Concentration & Interpore distance $\left(\mathrm{D}_{\text {int }}\right)$ & $\begin{array}{l}\text { Pore Diameter } \\
\text { Dp }(=2 \mathrm{r})\end{array}$ & $\begin{array}{l}\text { Porosity } \\
(\mathrm{P})\end{array}$ & Reference \\
\hline $\mathrm{H} 2 \mathrm{SO} 4$ & $25 \mathrm{~V}$ & $0.3 \mathrm{M}$ & $66.3 \mathrm{~nm}$ & $24 \mathrm{~nm}$ & $12 \%$ & 31 \\
\hline$(\mathrm{COOH})_{2}$ & $40 \mathrm{~V}$ & $0.3 \mathrm{M}$ & $105 \mathrm{~nm}$ & $31 \mathrm{~nm}$ & $8 \%$ & 31 \\
\hline $\mathrm{H}_{3} \mathrm{PO}_{4}$ & $195 \mathrm{~V}$ & $0.1 \mathrm{M}$ & $501 \mathrm{~nm}$ & $158.4 \mathrm{~nm}$ & $9 \%$ & 31 \\
\hline Citric Acid & $240 \mathrm{~V}$ & $2 \mathrm{M}$ & $600 \mathrm{~nm}$ & $180 \mathrm{~nm}$ & $10.0 \%$ & 61 \\
\hline
\end{tabular}

Table 3: Some of the parameter in which the optimum porosity is around

\begin{tabular}{|l|l|}
\hline \multicolumn{1}{|c|}{ Modification Method } & Comments \\
\hline Chemical Method & $\begin{array}{l}\text { Introduce functional groups by chemical mainly oxidative surface } \\
\text { treatment }\end{array}$ \\
\hline Plasma Treatment & By using plasma with oxygen \\
\hline Grafting Polymer & $\begin{array}{l}\text { UV and ionization radiation of membrane surface for monomer } \\
\text { grating }\end{array}$ \\
\hline Coating & $\begin{array}{l}\text { Deposition of hydrophilic or biocompatible materials, not very } \\
\text { stable }\end{array}$ \\
\hline $\begin{array}{l}\text { Molecular self Assembly or Layer by layer } \\
\text { (LBL) }\end{array}$ & LBL Assembly through chemical synthesis at the interface \\
\hline Casting Ultra thin barrier or lamination & $\begin{array}{l}\text { Deposition of gold, silver, copper, nickel\& other materials in ultra } \\
\text { thin layer }\end{array}$ \\
\hline
\end{tabular}

Table 4: Types of Modification Method

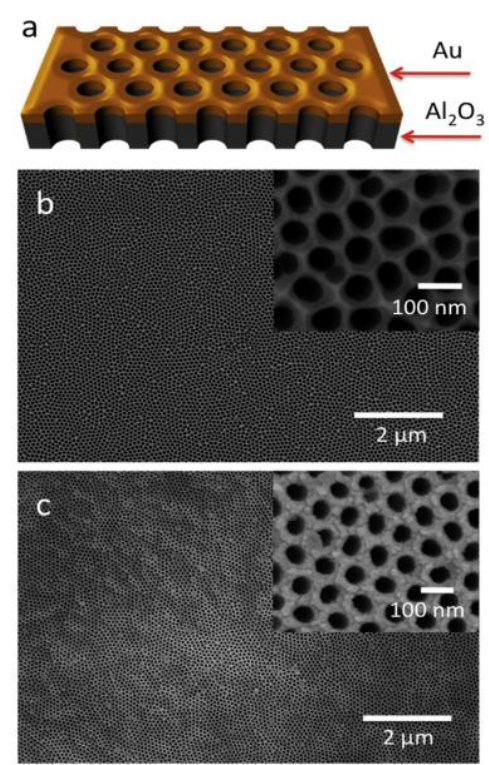

Figure 5 : (a) Illustration of honey-comb structure; SEM images of anodic porous alumina substrate before and after gold-coating of $25 \mathrm{~nm}$ are shown in figures (b) and (c), respectively. 


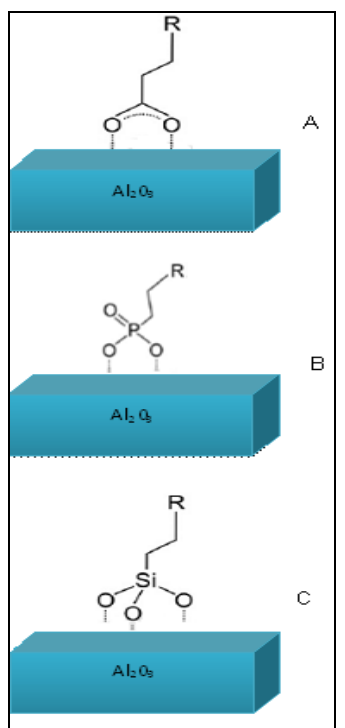

Figure: 6 Surface modification of APA. Examples of monolayer types that can be formed on APA, resulting from the adsorption of: a. Carboxylic acids, b. phosphonic acids, and c. organosilanes.
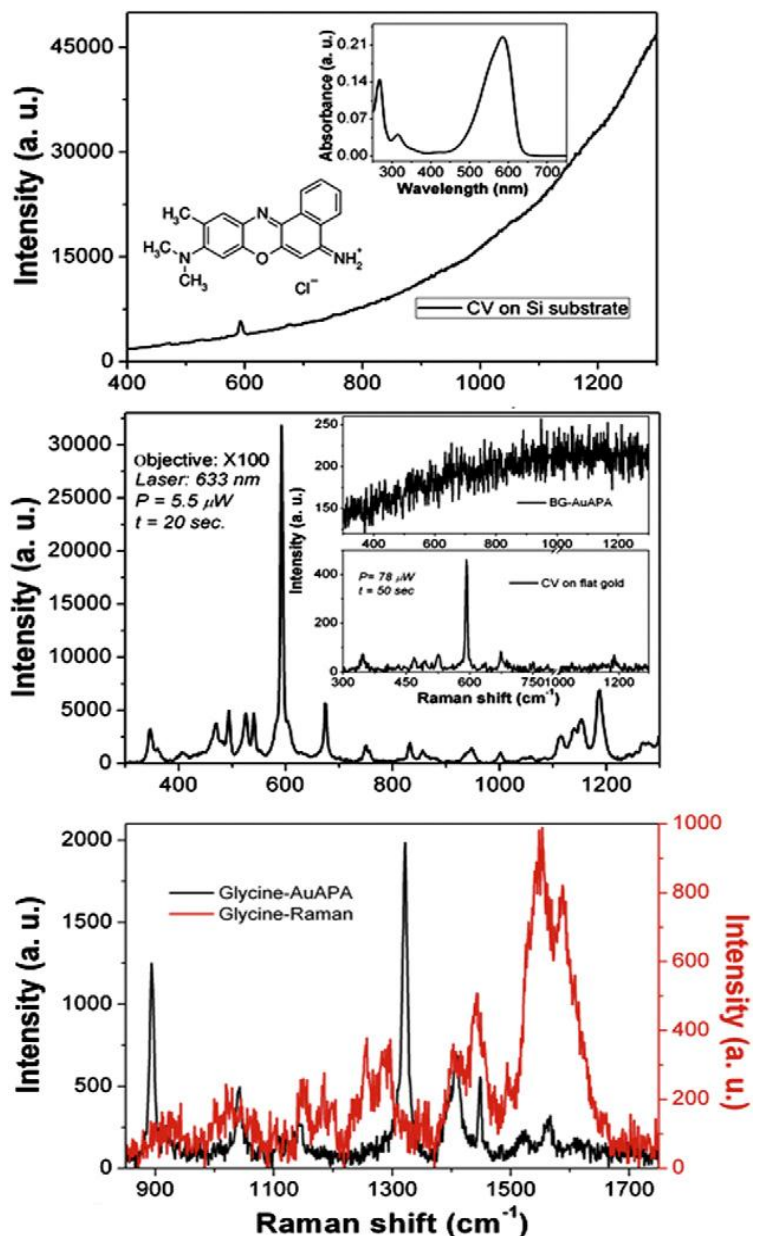

Figure : 7 (a) Raman spectrum of cresyl violet deposited on Si substrate, showing high fluorescence background in the range of 400-1550. Molecular structure and optical absorption spectrum of CV are shown in the inset of the same figure (b) SERS spectrum of CV is also illustrated, showing the CV spectrum due to an efficient fluorescence quenching by honey-comb structure. AuAPA SERS background spectrum and Raman spectrum of $\mathrm{CV}$, deposited on flat Au surface, are shown in the inset of figure (c) SERS and Raman spectrum of glycin (an amino acid). 


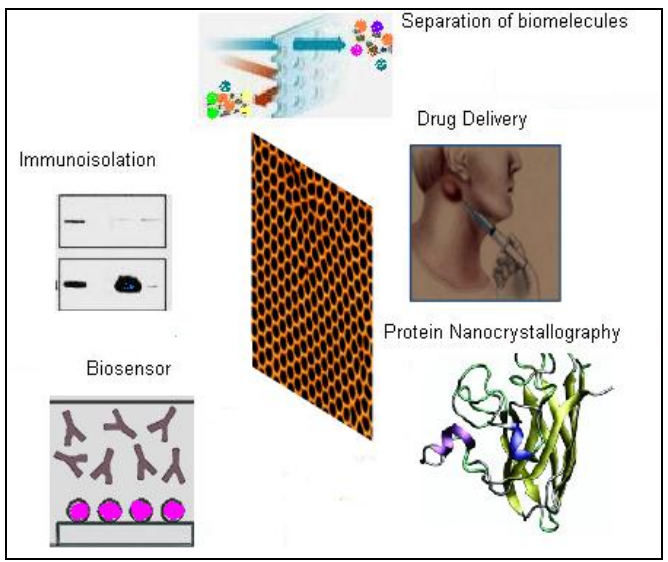

Figure : 8 Biomedical applications of nanoporous alumina

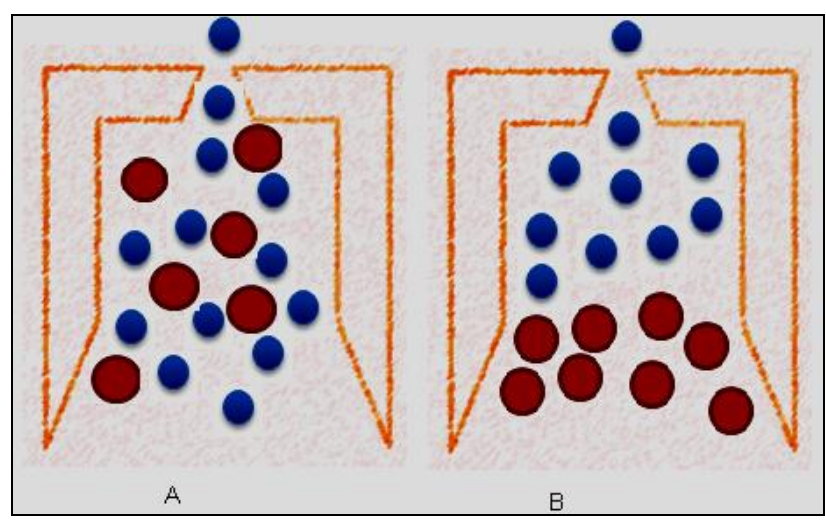

Figure 9: A plan comparison of charge-based separation via a Normal membrane (A) and a thin alumina nanoporous membrane (B).

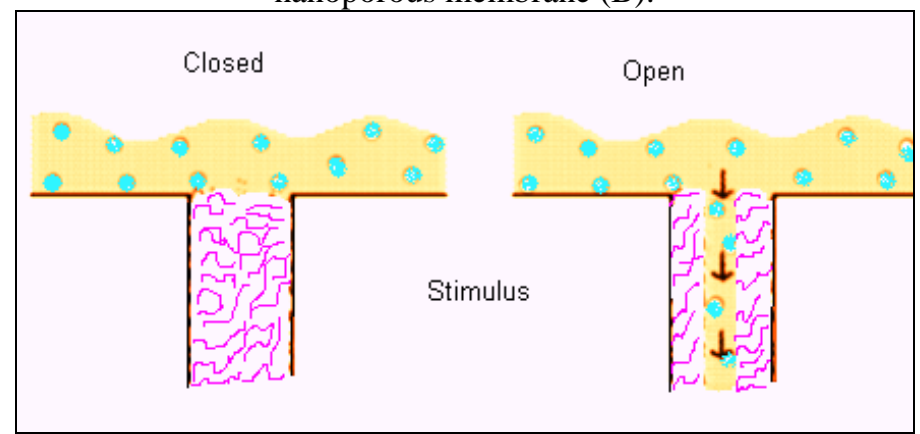

Figure 10: A plan design of nanoscale pores functionalized using responsive polymers for smart drug delivery. (Reproduce with permission from Ref. [Nanoporous Materials for Biomedical Devices, Biological material science JOM • March 2008 Shashishekar P. Adiga ]

\begin{tabular}{|l|l|l|l|}
\hline Cell Type & APA nanopore geometry & Cell growth promoting coating & References \\
\hline Rat pheochrocytoma (PC12) & $\begin{array}{l}\text { 1. Commerical APA membranes(Anodisc } \\
\text { Whatman International Ltd) with pore } \\
\text { diameters around } 200 \mathrm{~nm} \\
\text { 2. Gold coating of } 50 \mathrm{~nm}\end{array}$ & $\begin{array}{l}\text { Self-assembled monolayer } \\
\text { cysteamine and poly-L-lysine }\end{array}$ & 35 \\
\hline Primary hippocampal neurons & $\begin{array}{l}\text { Customised APA membranes } \\
\text { 1.Pitch sizes from 60-450 nm } \\
\text { 2.Pore depth varying from flat to } \\
\text { nanoporous substrates }\end{array}$ & $\begin{array}{l}\text { N-(-2-aminoethyl)-3- } \\
\text { aminopropyltrimethoxysilane }\end{array}$ & 36 \\
\hline $\begin{array}{l}\text { Primary rat embryonic } \\
\text { cortical neurons and looracic } \\
\text { gaglia neurons }\end{array}$ & $\begin{array}{l}\text { Customized APA nanopores: } \\
\text { 1. Interpore distances of 20 to 300 nm } \\
\text { 2.Porosity upto 40\% }\end{array}$ & $\begin{array}{l}\text { 1.Polysine for rat neurons } \\
\text { 2.Concanvalin A for insect } \\
\text { neurons }\end{array}$ & 37 \\
\hline $\begin{array}{l}\text { Mammalian neuronal cells } \\
\text { NG108-15) }\end{array}$ & $\begin{array}{l}\text { Customised alumina nanopores on CMOS } \\
\text { electrodes, produced with two-step } \\
\text { anodisation pitch sizes of } 17 \text { to 206 nm }\end{array}$ & N/A \\
\hline Primary hippocampal neuron & $\begin{array}{l}\text { Customized APA membranes embedded } \\
\text { in silicon diameters from } 25 \text { to } 100 \mathrm{~nm}\end{array}$ & Poly-L-lysine & 38,39 \\
\hline
\end{tabular}

Table 5: Overview of the Neuronal cell cultured on nanoporous APA substrates with versatile geometries 